\title{
Erratum to: Managing Online Anti-branding Consumer Behaviours: A Multiple Case Study Analysis in the Italian Landscape
}

\author{
Mario D'Arco and Vittoria Marino
}

\section{Erratum to:}

Chapter 10 in: F. J. Martínez-López et al. (eds.), Advances in National Brand and Private Label Marketing, Springer Proceedings in Business and Economics, https://doi.org/10.1007/978-3-319-92084-9_10

The original version of Chapter 10 was inadvertently published with incorrect author affiliation. The authors' affiliation must have read 'DISA-MIS, University of Salerno, Fisciano, Italy' instead of 'Department of Management and Information Technology, Curriculum Marketing and Communication, University of Salerno, Fisciano, Italy'. The chapter has been updated. 